\title{
Complicações neurológicas em anemia falciforme: avaliação neuropsicológica do desenvolvimento com o NEPSY
}

\author{
Neurological complications in sickle cell anemia: a developmental neuropsychological \\ assessment using NEPSY
}

Samantha Nunest ${ }^{1}$

Denise L. Miranda

Aline T. Reis ${ }^{3}$

Alice Maria S. Gramacho ${ }^{4}$

Rita Lucena ${ }^{5}$

Nayara Argollo

\begin{abstract}
Estudo de caso de duas crianças portadoras de anemia falciforme, com complicações neurológicas. Utilizou-se uma ampla bateria neuropsicológica - NEPSY. Uma criança apresentou acidente vascular cerebral com paresia de hemicorpo esquerdo, e a outra, ataque isquêmico transitório. As avaliações neuropsicológicas demonstraram que havia extenso prejuizo cognitivo no primeiro caso, em contraste com comprometimento leve no segundo. Baixas pontuações nas funções de atenção visual, memória operacional, linguagem, flexibilidade cognitiva, habilidades sensório-motora, visoespacial e visoconstrutiva. Rebaixamento intelectual e no desempenho acadêmico foram encontrados no paciente que sofreu o acidente isquêmico. A criança que foi acometida por ataque isquêmico transitório apresentou dispraxia motora e oromotora, diminuição da atenção visual e memória verbal. Estes achados corroboram com os dados encontrados na literatura e reforçam a relevância de conhecer a tipologia destas alterações para intervir precocemente na deficiência cognitiva, minimizando as repercussões no desenvolvimento cognitivo, acadêmico e psicossocial. Rev. Bras. Hematol. Hemoter. 2010;32(2):181-185.
\end{abstract}

Palavras-chave: Acidente vascular cerebral; ataque isquêmico transitório; anemia falciforme; criança.

\section{Introdução}

As complicações neurológicas da anemia falciforme (AF) são causadas pelo acidente vascular cerebral (AVC), ataques isquêmicos transitórios (AIT), infartos cerebrais silenciosos e diminuição do desempenho neuropsicológico.
A consequência do efeito cumulativo destas complicações é o funcionamento intelectual rebaixado, a diminuição do rendimento acadêmico, ${ }^{1}$ ou abandono escolar, que repercutirão na possibilidade destes indivíduos obterem melhor inserção no mercado de trabalho, além do resultante sofrimento psicoafetivo.

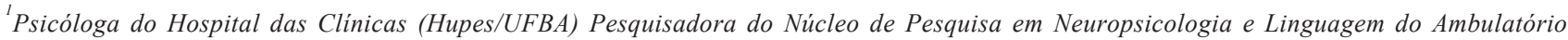
de Neurociências da UFBA.

${ }^{2}$ Pedagoga. Pesquisadora do Núcleo de Pesquisa em Neuropsicologia e Linguagem do Ambulatório de Neurociências da UFBA

Serviço de Hematologia e TMO do Hospital das Clínicas Porto Alegre-RS; Serviço de Hematologia do Hospital Luterano - Complexo Ulbra. Psicóloga. Pesquisadora do Núcleo de Pesquisa em Neuropsicologia e Linguagem do Ambulatório de Neurociências da UFBA.

${ }^{4}$ Psicóloga da Associação Pestalozzi de Salvador. Pesquisadora do Núcleo de Pesquisa em Neuropsicologia e Linguagem do Ambulatório de Neurociências da UFBA.

${ }^{5}$ Médica neuropediatra. Professora Adjunta da Faculdade de Medicina da UFBA; Coordenadora do Núcleo de Pesquisa em Neuropsicologia e Linguagem do Ambulatório de Neurociências da UFBA.

${ }^{6}$ Médica neuropediatra. Coordenadora Acadêmica do curso de pós-graduação de Especialização em Neuropsicologia; pesquisadora do Núcleo de Pesquisa em Neuropsicologia e Linguagem do Ambulatório de Neurociências da UFBA.

Núcleo de Pesquisa em Neuropsicologia e Linguagem do Ambulatório de Neurociências da Universidade Federal da Bahia - Salvador-BA

Correspondência: Nayara Argollo

Rua Altino Serbeto de Barros, 119, sala 104 - Itaigara

41.825-010 - Salvador-BA - Brasil

E-mail: nayaraargollo@uol.com.br

Doi: 10.1590/S1516-84842010005000044 
Crianças com AF necessitam de investigação neurológica com ressonância magnética do crânio (RMC), ultrassonografia transcraniana com Doppler e medidas de desempenho neuropsicológico. ${ }^{1}$ Estas avaliações devem ser transcritas para uma intervenção cognitiva que vise melhorar o desempenho escolar e abrandar as suas consequências.

O objetivo deste artigo é relatar dois estudos de caso de criancas com AF e complicação neurológica, avaliadas por uma ampla bateria neuropsicológica - NEPSY: Avaliação Neuropsicológica do Desenvolvimento, ${ }^{2}$ recentemente traduzida e adaptada para a língua portuguesa. ${ }^{3}$

\section{Relato de Caso}

\section{Caso 1 (C1)}

Paciente do sexo feminino, 8 anos de idade, destra, mulata, diagnóstico de AF aos 4 anos. A genitora usou álcool e fumo na gestação. Parto vaginal, a termo (pesou 3.500 g); taquipneia transitória. Desenvolvimento neuropsicomotor (DNPM) nos parâmetros da normalidade. Infecções respiratórias nos primeiros anos de vida e uso de ácido fólico após o diagnóstico. Aos 6,5 anos, hemiparesia esquerda súbita, sendo diagnosticada isquemia no território da artéria cerebral média direita pela RMC e, deste então, instituído tratamento com transfusões de concentrado de hemácias, uma bolsa/mês. Na época da avaliação, estudava em escola municipal, não estava alfabetizada, repetia a $2^{\mathrm{a}}$ série. Apresentava dificuldade em leitura, escrita e cálculo. O pai, serralheiro, concluiu o ensino médio (EM), e a mãe, dona de casa, estudou até a $4^{\mathrm{a}}$ série (Tabela 1). Dois irmãos sem AF. QI estimado foi médio inferior. Resultados da avaliação neuropsicológica encontram-se na Tabela 2.

\section{Caso 2 (C2)}

Paciente do sexo masculino, 8 anos e 10 meses de idade, destro, negro, diagnóstico de AF ao nascimento. Mãe portadora de AF. Gravidez e parto vaginal sem intercorrências (pesou 2.850kg); DNPM dentro dos marcos; uso de ácido fólico a partir de um ano de idade. Aos 4 anos, internado com quadro sugestivo de AVC, com envolvimento motor global, pior em membros inferiores, com duração de 72 horas e lenta recuperação. A RMC afastou isquemia e hemorragias. Diagnosticado AIT. No período da avaliação neuropsicológica, cursava a $3^{\mathrm{a}}$ série do ensino fundamental (EF) em escola particular. Genitor com EF incompleto, montador de móveis; genitora com EM completo, dona de casa. Um irmão sem AF (Tabela 1). QI Estimado médio superior. Dados da avaliação neuropsicológica constam na Tabela 2.

\section{Discussão}

Distúrbios cognitivos sutis são detectados apenas mediante a avaliação neuropsicológica. O objetivo do artigo foi descrever dois pacientes com $\mathrm{AF}$, um com franco quadro
Tabela 1. Características gerais dos casos clínicos

\begin{tabular}{lcc}
\hline Característica & Caso 1 & Caso 2 \\
\hline $\begin{array}{l}\text { Sexo } \\
\text { Idade (anos, meses) }\end{array}$ & feminino & masculino \\
Classe socioeconômica & a $2 \mathrm{~m}$ & $8 \mathrm{a} 10 \mathrm{~m}$ \\
$\begin{array}{l}\text { Escolaridade da mãe } \\
\text { (anos de estudo) }\end{array}$ & $\mathrm{C}$ & $\mathrm{C}$ \\
$\begin{array}{l}\text { Discrepância série-idade } \\
\text { (anos de atraso) }\end{array}$ & 4 & 11 \\
$\begin{array}{l}\text { Estimativa de Ql } \\
\text { (escore ponderado) }\end{array}$ & 1 & 0 \\
\hline
\end{tabular}

1. ABEP $^{4}$

de AVC isquêmico e outro com AIT. O C1 apresentava diagnóstico neurológico de hemiplegia esquerda secundária e dificuldades de aprendizagem, e o C2 em queixas cognitivas.

No QI Estimado (QIE) $)^{5,6}$ para triagem intelectiva, C1 apresentou quociente dentro da variação de dois desviospadrão, mas na faixa inferior da normalidade, e C2, na faixa médio-superior. O QI é preditor de desempenho acadêmico ${ }^{5} \mathrm{e}$ isto corrobora com as queixas de dificuldade de aprendizado do primeiro caso. A inteligência sofre influência de componentes genéticos e ambientais. ${ }^{7}$ Neste contexto, ambos interagiram: a doença crônica, a anemia, o AVC isquêmico, a baixa escolaridade materna e condições acadêmicas desfavoráveis. $\mathrm{C} 2$, apesar do fator genético negativo, apresentava fatores protetores (maior escolaridade materna ${ }^{7}$ e frequentava escola particular). Sem avaliação pré-mórbida não se pode inferir sobre QI anterior. A classe socioeconômica, similar nos dois casos, possivelmente não influenciou esta diferença.

$\mathrm{O}$ QI poderá variar conforme o grau de comprometimento neurológico. Watkins et al. ${ }^{8}$ compararam o funcionamento intelectivo de crianças com AF e infarto clínico, infarto silencioso, e sem infarto, com controles saudáveis, e verificaram que aquelas com infarto clínico tiveram os menores escores, que foi confirmado por outros estudos. ${ }^{1}$ Investigações comparativas entre crianças com AIT não têm sido publicadas. Conhecer o escore do QI não informa sobre as habilidades potenciais e limitações das funções cognitivas do indivíduo. A avaliação neuropsicológica pretende, entre os seus objetivos, responder a esta questão.

As avaliações neuropsicológicas foram realizadas com o NEPSY, ${ }^{2}$ uma bateria neuropsicológica que analisa cinco áreas cognitivas: 1) Atenção/Funções Executivas (AFE - 6 subtestes); 2) Linguagem (LGM - 6 subtestes); 3) Função Sensório-motora (FSM - 6 subtestes); 4) Processamento visoespacial (PVE - 4 subtestes); 5) Aprendizado e Memória (APM - 5 subtestes). Os subtestes são agrupados em Partes Central e Expandida. A primeira utilizada para diagnóstico inicial e, conhecendo-se os pontos fracos e fortes da cognição, complementada com os subtestes da Parte Expandida. Crianças com AF devem ser avaliadas de forma ampla, uma 
Tabela 2. Escores dos subtestes da Bateria NEPSY

\begin{tabular}{|c|c|c|c|c|c|}
\hline $\begin{array}{r}\mathrm{D} \\
\text { (escore ponderad } \\
\text { (escore pon } \\
\end{array}$ & $\begin{array}{l}\text { nínios } \\
-100 \pm 10^{* *} / \text { percentil) } \\
\text { oteste } \\
\text { rado }-10 \pm 3^{* *} \text { ) }\end{array}$ & Caso 1 & Interpretação & Caso 2 & Interpretação \\
\hline \multicolumn{2}{|l|}{ Atenção/Funções Executivas } & $63 / 1$ & Abaixo & $98 / 45$ & Média \\
\hline \multirow{4}{*}{ Partes } & Torre & 9 & Média & 12 & Acima \\
\hline & Atenção auditiva & 3 & Muito abaixo & 11 & Média \\
\hline & Atenção visual & 3 & Muito abaixo & 6 & Abaixo \\
\hline & Estátua & $26-75^{\star}$ & Média & $>75^{\star}$ & Acima \\
\hline \multirow[t]{2}{*}{ Expandida } & Fluência em desenhos & 2 & Muito abaixo & 7 & Limítrofe \\
\hline & Batendo na mesa & $>75^{*}$ & Média & $11-25^{*}$ & Abaixo \\
\hline Linguagem & & $74 / 4$ & Muito Abaixo & $95 / 37$ & Média \\
\hline \multirow{4}{*}{ Partes } & Processamento fonológico & 4 & Muito Abaixo & 9 & Média \\
\hline & Velocidade de nomeação & 8 & Média & 10 & Média \\
\hline & Compreendendo instrução & 5 & Abaixo & 9 & Média \\
\hline & Repetindo pseudopalavras & 14 & Acima & 11 & Média \\
\hline \multirow[t]{2}{*}{ Expandida } & Sequências oromotoras & $\leq 2^{*}$ & Muito Abaixo & $3-10^{*}$ & Muito abaixo \\
\hline & Fluência verbal & 5 & Abaixo & 12 & Acima \\
\hline \multicolumn{2}{|l|}{ Função Sensório-motora } & $65 / 1$ & Muito abaixo & $77 / 6$ & Abaixo \\
\hline \multirow{3}{*}{ Central } & Tocando a ponta dos dedos & 4 & Muito abaixo & 8 & Média \\
\hline & Imitando posições da mão & 5 & Abaixo & 10 & Média \\
\hline & Precisão visuo-motora & 6 & Abaixo & 3 & Muito abaixo \\
\hline \multirow{3}{*}{ Expandida } & Sequências motoras manuais & $11-25^{\star}$ & Abaixo & $26-75^{\star}$ & Média \\
\hline & Discriminando dedos (Dominante) & $11-25^{\star}$ & Abaixo & $26-75^{*}$ & Média \\
\hline & $\begin{array}{l}\text { Discriminando dedos } \\
\text { (Não-dominante) }\end{array}$ & $\leq 2^{*}$ & Muito abaixo & $26-75^{*}$ & Média \\
\hline \multicolumn{2}{|l|}{ Processamento Visuoespacial } & $57 / 0,1$ & Muito abaixo & $82 / 10$ & Limítrofe \\
\hline \multirow{4}{*}{ Expandida } & Copiando desenhos & 2 & Muito abaixo & 7 & Limítrofe \\
\hline & Flechas & 3 & Muito abaixo & 8 & Média \\
\hline & Construindo com blocos & 4 & Muito abaixo & 8 & Média \\
\hline & Encontrando caminhos & $3-10^{*}$ & Muito abaixo & $26-75^{\star}$ & Média \\
\hline \multicolumn{2}{|l|}{ Aprendizado e Memória } & $91 / 27$ & Média & $86 / 18$ & Limítrofe \\
\hline \multirow{5}{*}{ Partes } & Memória para faces & 8 & Média & 9 & Média \\
\hline & Memória para nomes & 6 & Abaixo & 7 & Limítrofe \\
\hline & Memória narrativa & 12 & Acima & 8 & Média \\
\hline & Repetindo frases & 3 & Muito abaixo & 6 & Abaixo \\
\hline & Aprendendo uma lista & 10 & Média & 9 & Média \\
\hline
\end{tabular}

* Percentual; ** Média \pm Desvio-padrão dos Escores Ponderados do NEPSY

vez que diversas funções podem estar prejudicadas ou sujeitas a comprometimento, durante a evolução da doença.

$\mathrm{C} 1$ apresentou baixos escores em todos os domínios, exceto em APM. Nos domínios FSM e PVE, os resultados estiveram rebaixados, demonstrando comprometimento global. Esta paciente sofreu infarto em hemisfério direito (HD), cujas funções incluem o PVE (não verbal). Esta última integra a entrada visual com a saída motora, permitindo a realização de cópias, desenhos, construções, etc. É responsável pelo julgamento espacial sem saída motora, como perceber distâncias e direções, usando como referência o próprio corpo. Estas habilidades são importantes para o aprendizado acadêmico formal. A hemiparesia explica o baixo desempenho sensório-motor.
C2 também apresentou os piores resultados nestes dois domínios. O rebaixamento na FSM deveu-se à Precisão Visomotora (avalia velocidade e precisão da coordenação refinada da mão dominante). Este baixo desempenho possivelmente contribuiu para o escore rebaixado em Copiando Desenho (exige saída motora), assim como o subteste do domínio AFE, Fluência para Desenhos. A coordenação oromotora (subteste Sequências Oromotoras) também apresentou baixa porcentagem, sugerindo que a dispraxia envolveu o movimento orofacial. Resumindo, C2 tinha dispraxia leve global, envolvendo atividades de lápis e papel, muito utilizadas em tarefas escolares, e dispraxia oromotora.

Pesquisas sobre as habilidades visoespacias e sensório-motoras em crianças com $\mathrm{AF}$ têm resultados conflitantes, 
e, em sua maioria, investigadas separadamente. Armstrong et al. ${ }^{9}$ encontraram rebaixamento no desempenho viso-motor em crianças com infarto clínico comparadas com aquelas com infarto silencioso ou sem infarto. Entretanto, Brown et al. ${ }^{10}$ em estudo semelhante, não encontraram diferenças.

A FSM e a LGM são os pilares do desenvolvimento cognitivo. Facilidades ou dificuldades nestas áreas influenciarão outros domínios. C1 obteve baixa pontuação nos subtestes de linguagem expressiva (disfasia de expressão). Esta é uma função do hemisfério contralateral ao lesado neste paciente, sugerindo que o hemisfério esquerdo também estava comprometido. Ambos os pacientes obtiveram baixo desempenho na memória verbal (Repetindo Frases memória operacional e Memória para Nomes - memória verbal de curta e longa duração). De acordo com Berkelhammer et al., ${ }^{11}$ em revisão sobre o tema, os estudos sugerem que os déficits em LGM estão relacionados à lateralização e ao volume da lesão. C1, com infarto no HD, apresentou sinais de comprometimento à esquerda. Supõese que este tenha sido secundário a infartos silenciosos pós-infarto clínico, ou a danos fisiológicos provenientes à doença crônica, com impacto negativo no desenvolvimento da linguagem. ${ }^{11}$

As funções cognitivas mais tardiamente amadurecidas na criança são AFE, que influenciam e são influenciadas por outras funções. FE são processos complexos usados para dirigir o comportamento a determinado objetivo e incluem: inibição, planejamento, organização, processamento mental sequencial, monitoramento da resposta, tomada de decisão, julgamento, raciocínio, flexibilidade mental e memória operacional, ${ }^{1}$ sob o direcionamento da atenção. Os dois casos apresentaram rebaixamento neste domínio. C1 com desatenção visual e auditiva (Atenção Visual e Atenção e Conjunto de Respostas Auditivas), e rebaixamento da flexibilidade mental, organização e categorização (Fluência para Desenhos e Fluência Verbal), com preservação da inibição (Estátua e Torre) e do planejamento (Torre). A desatenção visual de $\mathrm{C} 2$ provavelmente contribuiu para os prejuízos nas tarefas visomotoras, uma vez que a entrada visual e o PVE encontraramse preservados (Flechas e Encontrando Caminhos). O baixo desempenho em Batendo na Mesa pode ser explicado pela dispraxia. Os déficits em AFE relacionam-se com a presença e a gravidade da lesão. Podem ser encontrados em até 53\% das crianças com infarto silencioso e em $13 \%$ daquelas sem infarto. ${ }^{7}$ Lesões frontais ou parietais prejudicam a atenção. Nos casos, predominam desatenção sem grande impacto nas FE, sugerindo envolvimento posterior do HD.

Concluindo, a análise neuropsicológica dos pacientes demonstrou alteração em vários domínios cognitivos, envolvendo funções de ambos os hemisférios cerebrais: grave em $\mathrm{C} 1$ (dificuldades visoespaciais e de linguagem) e leve em C2 (dispraxia motora e oromotora, desatenção visual). C1 já cursava com dificuldades escolares e $\mathrm{C} 2$ era de risco para futuro prejuízo acadêmico, devido ao aumento das exigências escolares ou surgimento de novas desabilidades. A intervenção neuropsicológica para tratamento e prevenção foi indicada nos dois.

Por tratar-se de doença hematovascular crônica e evolutiva, pacientes com AF necessitam de avaliação neuropsicológica periódica e acompanhamento regular. Como as ausências escolares, ocasionadas por internações recorrentes, são frequentes, a participação em programas de inclusão socioeducacional deve ser indicada. Conhecer a tipologia das alterações e da deficiência cognitiva favorece a aplicação de medidas preventivas e a possibilidade de intervenção precoce, minimizando as repercussões das complicações neurológicas no desenvolvimento cognitivo, acadêmico e psicossocial.

\section{Abstract}

This is a case study of two children with sickle cell anemia and neurological complications. An extensive series of neuropsychological tests - NEPSY was used in the evaluation of the children. One child had suffered an ischemic stroke with left hemiparesis and the other, transient ischemic attack. The neuropsychological assessment showed extensive cognitive damage in the first case, in contrast to mild impairment in the second. Low scores were found for tasks of visual attention, operational memory, language, cognitive flexibility and for sensory-motor, visuospatial and visuoconstructive skills. Low intellectual and academic performance was found in the patient who suffered ischemic stroke. The child who suffered transient ischemic attack showed motor and oromotor dyspraxia, and decreased visual attention and verbal memory. These findings corroborate published data and reinforce both the importance of identifying the types of changes in patients and providing early intervention when there is any learning disability, thereby minimizing the impact of neurological complications during cognitive, academic and psychosocial developmen. Rev. Bras. Hematol. Hemoter. 2010; 32(2):181-185.

Key words: Stroke; ischemic attack, transient; anemia; child.

\section{Referências Bibliográficas}

1. Wang WC. Central nervous system complications of sickle cell disease in children: an overview. Child Neuropsychol. 2007;13 (2):103-19.

2. Korkman M, Kirk U, Kemp S. NEPSY: A Developmental neuropsychological Assessment. San Antonio, TX: The Psychological Corporation, 1998.

3. Argollo N, Bueno OFA, Shayer B, Godinho K, Abreu K, Duran P, et al. Avaliação transcultural da bateria NEPSY - Avaliação neuropsicológica do desenvolvimento: estudo piloto. Avaliação psicológica. No prelo, 2009.

4. Associação Brasileira de Empresas de Pesquisa (ABEP), 2003. Dados com base no Levantamento Socioeconômico - Ibope. [Internet]. 2000[2009 maio 10]. Disponível em: http://www.abep.org.

5. Wechsler D. Manual for the Wechsler Intelligence Scale - Revised. New York: Psychological Corporation, 1974. 
6. Lezak MD, Howieson DB, Loring DW. Neuropsychological Assessment, (4th ed.), New York: Oxford University Press, 2004 .

7. Schatz J, Finke R, Roberts CW. Interactions of biomedical and environmental risk factors for cognitive development: a preliminary study of sickle cell disease. J Dev Behav Pediatr. 2004;25(5):303-10.

8. Watkins KE, Hewes DK, Connelly A, Kendall BE, Kingsley DP, Evans JE, et al. Cognitive deficits associated with frontal-lobe infarction in children with sickle cell disease. Dev Med Child Neurol. 1998;40(8):536-43.

9. Armstrong FD, Thompson RJ Jr, Wang W, Zimmerman R, Pegelow $\mathrm{CH}$, Miler $\mathrm{S}$, et al. Cognitive functioning and brain magnetic resonance imaging in children with sickle cell disease. Neuropsychology Committee of the Cooperative Study of Sickle Cell Disease. Pediatrics. 1996;97(6):864-70.

10. Brown RT, Davies PC, Lambert R, Hsu L, Hopkins K, Eckman J. Neurocognitive functioning and magnetic resonance imaging in children with sickle cell disease. J Pediatr Psychol. 2000;25(7): 503-13.

11. Berkelhammer LD, Williamson AL, Sanford SD, Dirksen CL, Sharp WG, Margulies AS, et al. Neurocognitive sequelae of pediatric sickle cell disease: a review of the literature. Child Neuropsychol. 2007;13(2):120-31.

Suporte Financeiro: Este estudo está vinculado ao Projeto "Anemia Falciforme em Crianças e Adolescentes na Bahia: Aspectos Audiológicos e Neuropsicológicos" financiado pelo CNPQ.

Avaliação: Editor e dois revisores externos

Conflito de interesse: sem conflito de interesse

Recebido: 07/06/2009

Aceito: 04/08/2009 